\title{
Kinetic analysis as a tool to distinguish pathway complexity in molecular assembly : an unexpected outcome of structures in competition
}

\author{
Citation for published version (APA): \\ Zwaag, van der, D., Pieters, P. A., Korevaar, P. A., Markvoort, A. J., Spiering, A. J. H., Greef, de, T. F. A., \& \\ Meijer, E. W. (2015). Kinetic analysis as a tool to distinguish pathway complexity in molecular assembly : an \\ unexpected outcome of structures in competition. Journal of the American Chemical Society, 137(39), 12677- \\ 12688. https://doi.org/10.1021/jacs.5b08138
}

\section{Document license: \\ TAVERNE}

DOI:

10.1021/jacs.5b08138

Document status and date:

Published: 01/01/2015

\section{Document Version:}

Publisher's PDF, also known as Version of Record (includes final page, issue and volume numbers)

\section{Please check the document version of this publication:}

- A submitted manuscript is the version of the article upon submission and before peer-review. There can be important differences between the submitted version and the official published version of record. People interested in the research are advised to contact the author for the final version of the publication, or visit the $\mathrm{DOI}$ to the publisher's website.

- The final author version and the galley proof are versions of the publication after peer review.

- The final published version features the final layout of the paper including the volume, issue and page numbers.

Link to publication

\footnotetext{
General rights

- You may freely distribute the URL identifying the publication in the public portal. follow below link for the End User Agreement:

www.tue.nl/taverne

\section{Take down policy}

If you believe that this document breaches copyright please contact us at:

openaccess@tue.nl

providing details and we will investigate your claim.
}

Copyright and moral rights for the publications made accessible in the public portal are retained by the authors and/or other copyright owners and it is a condition of accessing publications that users recognise and abide by the legal requirements associated with these rights.

- Users may download and print one copy of any publication from the public portal for the purpose of private study or research.

- You may not further distribute the material or use it for any profit-making activity or commercial gain

If the publication is distributed under the terms of Article $25 \mathrm{fa}$ of the Dutch Copyright Act, indicated by the "Taverne" license above, please 


\title{
Kinetic Analysis as a Tool to Distinguish Pathway Complexity in Molecular Assembly: An Unexpected Outcome of Structures in Competition
}

\author{
Daan van der Zwaag, ${ }^{\dagger,}$ Pascal A. Pieters, ${ }^{\dagger}$ Peter A. Korevaar, ${ }^{\dagger,}$ Albert J. Markvoort, ${ }^{\dagger, \S}$ A. J. H. Spiering,
}

Tom F. A. de Greef, $*, \dagger, \S$ and E. W. Meijer*, ${ }^{\dagger, t}$

${ }^{\dagger}$ Institute for Complex Molecular Systems, ${ }^{\ddagger}$ Laboratory of Macromolecular and Organic Chemistry, and ${ }^{\S}$ Computational Biology Group, Eindhoven University of Technology, P.O. Box 513, 5600 MB Eindhoven, The Netherlands

Supporting Information

\begin{abstract}
While the sensitive dependence of the functional characteristics of selfassembled nanofibers on the molecular structure of their building blocks is well-known, the crucial influence of the dynamics of the assembly process is often overlooked. For natural protein-based fibrils, various aggregation mechanisms have been demonstrated, from simple primary nucleation to secondary nucleation and off-pathway aggregation. Similar pathway complexity has recently been described in synthetic supramolecular polymers and has been shown to be intimately linked to their morphology. We outline a general method to investigate the consequences of the presence of multiple assembly pathways, and show how kinetic analysis can be used to distinguish different assembly mechanisms. We illustrate our combined experimental and theoretical approach by studying the aggregation of chiral bipyridine-extended 1,3,5-benzenetricarboxamides $(B i P y-1)$ in $n$-butanol as a model system. Our workflow consists of nonlinear least-

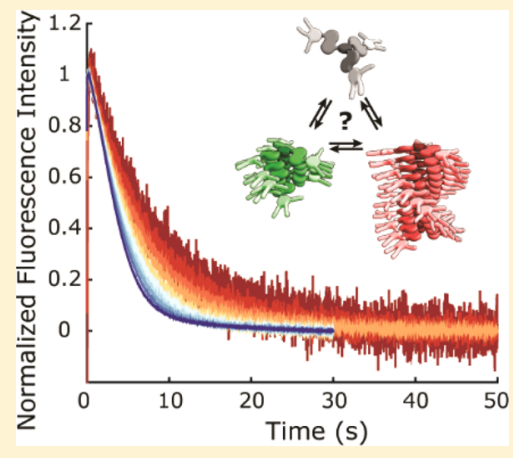
squares analysis of steady-state spectroscopic measurements, which cannot provide conclusive mechanistic information but yields the equilibrium constants of the self-assembly process as constraints for subsequent kinetic analysis. Furthermore, kinetic nucleation-elongation models based on one and two competing pathways are used to interpret time-dependent spectroscopic measurements acquired using stop-flow and temperature-jump methods. Thus, we reveal that the sharp transition observed in the aggregation process of BiPy-1 cannot be explained by a single cooperative pathway, but can be described by a competitive two-pathway mechanism. This work provides a general tool for analyzing supramolecular polymerizations and establishing energetic landscapes, leading to mechanistic insights that at first sight may seem unexpected and counterintuitive.
\end{abstract}

\section{INTRODUCTION}

Self-assembly is an efficient method to create nanostructured materials, ${ }^{1}$ which show great promise for applications ranging from advanced materials ${ }^{2}$ and organic electronics ${ }^{3}$ to biomedical engineering. ${ }^{4}$ In particular, self-assembly of small molecules into one-dimensional supramolecular polymers ${ }^{5}$ can provide structures suitable for use as nanoelectronic elements ${ }^{6}$ or artificial extracellular matrix. ${ }^{7}$ The relative orientation of molecules that make up these aggregates is a critical factor that determines their functional properties, ${ }^{8}$ and thus achieving control over molecular assembly is important in optimizing performance characteristics.

The stacking geometry of monomers inside a supramolecular polymer is partially predetermined by their molecular structure, ${ }^{9}$ but recent work shows that many supramolecular polymers display several morphologies ${ }^{10}$ corresponding to different orientations of the monomer in the aggregate. ${ }^{8 a, 11}$ These different aggregate morphologies can be selectively created by tuning experimental conditions such as concentration $(C)$ and temperature $(T)$, resulting in the predominance of a particular aggregate state at a specific point in $(C, T)$ - space. ${ }^{12}$ Previous work has shown that steady-state spectroscopic measurements combined with subsequent modeling can be used to investigate complex self-assembly processes, yielding important information about the distribution of aggregate species. ${ }^{13}$ However, the mechanistic details of the formation and interconversion of these aggregate morphologies cannot be investigated using equilibrium data alone, hindering our ability to rationally engineer self-assembled one-dimensional nanostructures.

Natural systems achieve advanced functionality through tightly controlled self-assembly kinetics, as cells use supramolecular polymers to provide mechanical strength in the cytoskeleton $^{14}$ and to act as sophisticated signaling platforms. ${ }^{15}$ It has become increasingly clear that the dynamics of (dis)assembly are also critical in determining the final nanoscale morphology ${ }^{16}$ of synthetic materials. As such, investigating the time-dependent behavior of supramolecular polymers through kinetic experiments ${ }^{17}$ and models is crucial in order to

Received: August 3, 2015

Published: September 10, 2015 


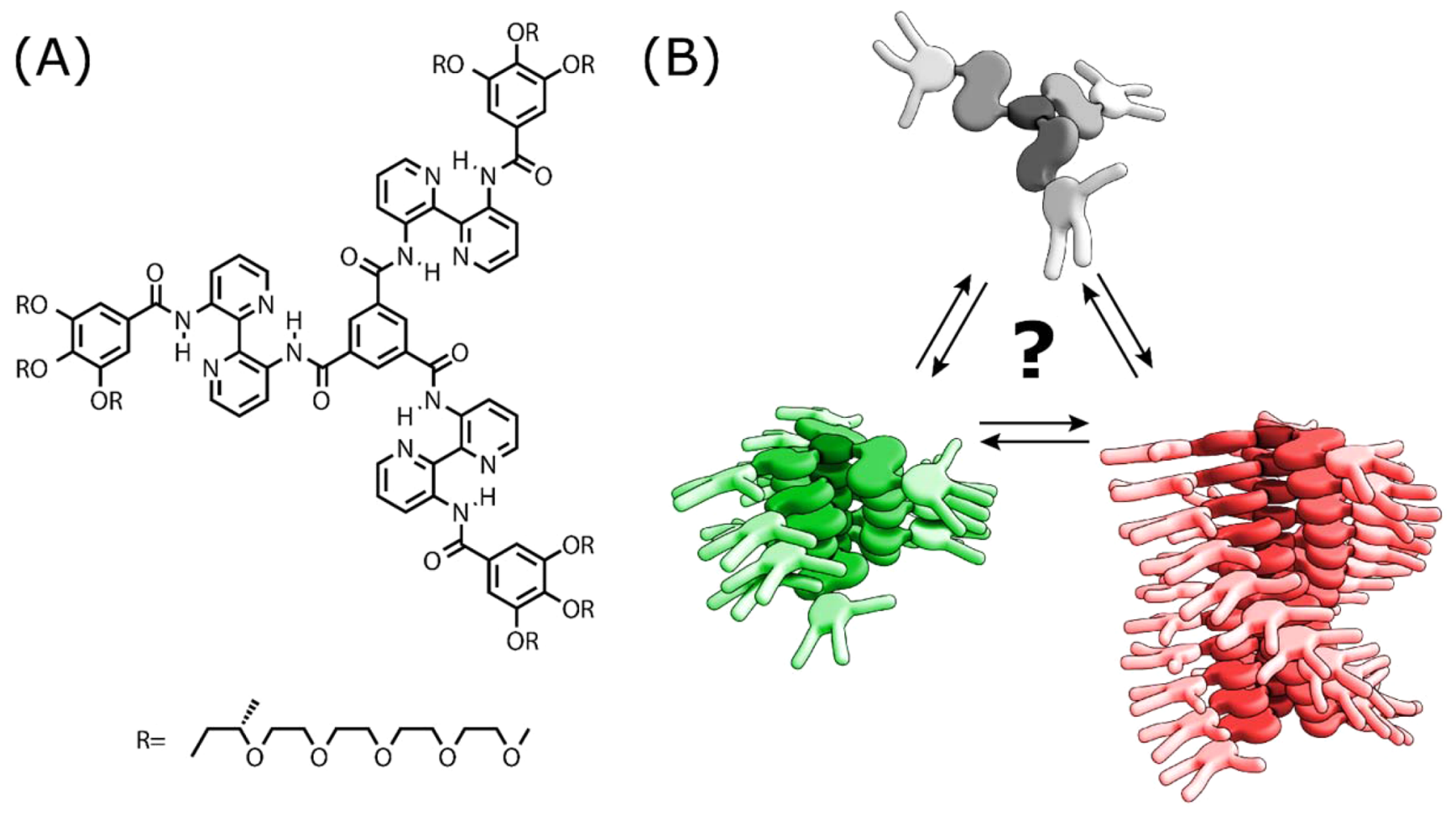

Figure 1. (A) Structure of the discotic molecule BiPy-1. (B) Depending on concentration and temperature, BiPy-1 self-assembles into multiple, spectrally distinct aggregate states due to a combination of hydrophobic effects and aromatic interactions.

understand their self-assembly mechanisms. The first kinetic models for one-dimensional aggregation were designed for protein-based fibrils by Oosawa and Kasai as early as the $1960 \mathrm{~s}^{18}$ describing the self-assembly process as a series of consecutive monomer addition reactions. Subsequently, more advanced kinetic models have been proposed describing selfassembly into a single aggregate state by homogeneous nucleation, fragmentation and recombination ${ }^{19}$ or secondary nucleation. $^{20}$ Recently, it was shown that the presence of multiple aggregation pathways strongly affects the kinetics of protein fibril formation, ${ }^{21}$ suggesting that incorporation of multiple self-assembly pathways in kinetic models greatly improves their general applicability. ${ }^{22}$ Bridging the gap between natural protein fibrils and synthetic nanofibers, Korevaar et al. have applied kinetic models to show that the various aggregate states observed in synthetic supramolecular polymers influence their self-assembly kinetics in a similar fashion. ${ }^{23}$ Experimentally, the groups of Takeuchi, ${ }^{24}$ Aida $^{25}$ and Würthner ${ }^{26}$ have made great progress in achieving kinetic control over supramolecular polymerization, granting access to aggregates with unique properties. ${ }^{27}$ The above examples clearly illustrate that complex self-assembly mechanisms can only be fully understood in kinetic terms, and thus appropriate experiments and models are required to rationally engineer $\pi$-conjugated materials with tailored properties. However, so far clear guidelines on how to design such a comprehensive analysis, and how to validate the applied models for a self-assembly process, are lacking.

Here, we address manifestations of pathway complexity using the aggregation of bipyridine-extended 1,3,5-benzenetricarboxamide $(B i P y-1)$ as an example. $C_{3}$-symmetric bipyridine discotics self-assemble into chiral, one-dimensional aggregates in a wide variety of solvents depending on the nature of the solubilizing side chains. For example, bipyridine-discs function- alized with alkyl side chains associate into helical assemblies in methylcyclohexane upon decreasing the temperature or increasing the concentration. ${ }^{28}$ In contrast, oligoethylene glycol-appended $B i P y-1$ self-assembles in more polar solvents, such as alcohols and water. ${ }^{29}$ Previous investigation of BiPy-1 aggregation in $n$-butanol has suggested the presence of multiple aggregate states, but the interconversion mechanism has so far remained elusive. ${ }^{30}$ In this work, the details of these aggregate states and their abundance under different conditions are analyzed using steady-state spectroscopic measurements. Detailed, broadly applicable thermodynamic models have been created to simulate the behavior of BiPy-1 under different conditions, and we show how to apply these to delineate the spectroscopic results. The multiple aggregate states can be interpreted as one nucleation-elongation pathway, or two competing pathways, and thus variant models for these two scenarios have been created. Both approaches are able to satisfactorily describe the data, underlining the difficulty of extracting mechanistic information using equilibrium models. In order to differentiate between the two mechanisms, the exact functional relation between the aggregate states is probed using time-resolved temperature-jump spectroscopy. Applying the data from the thermodynamic simulations as constraints, kinetic modeling using temperature-dependent one- and twopathway assembly schemes is then utilized to interpret the kinetic experiments, allowing us to select the correct assembly mechanism. Our analysis and workflow serves as a general method that can be used by supramolecular chemists to identify the presence of multiple pathways in one-dimensional supramolecular polymerization.

\section{RESULTS AND DISCUSSION}

2.1. Self-Assembly of BiPy-1. The bipyridine-extended 1,3,5-benzenetricarboxamide derivative BiPy-1 (Figure 1A) has 
(A)

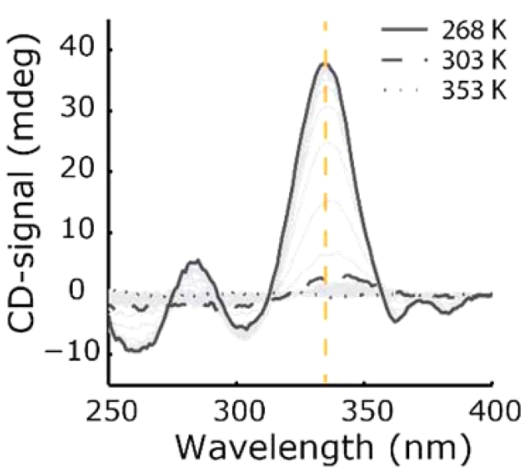

(D)

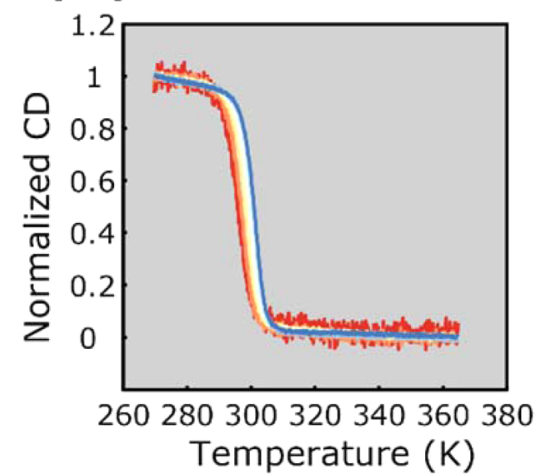

(B)

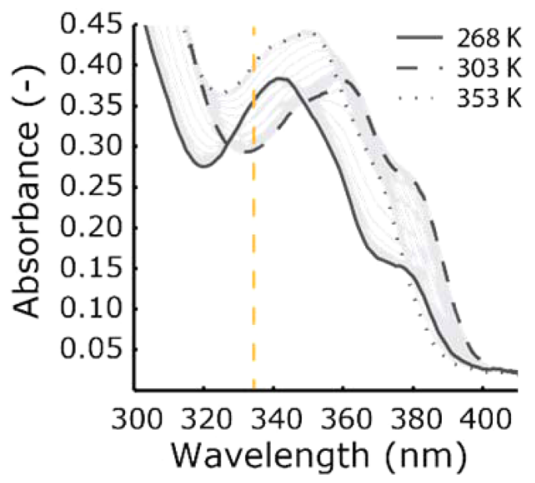

(E)

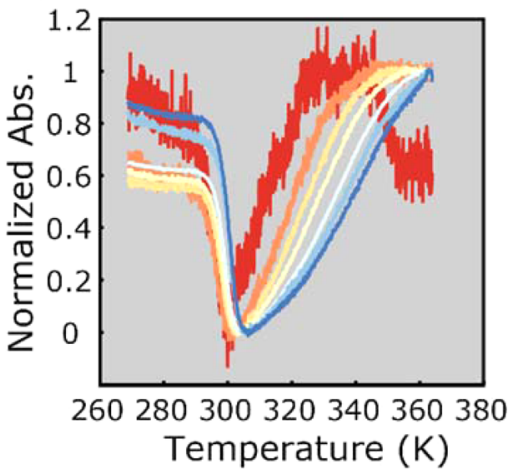

(C)

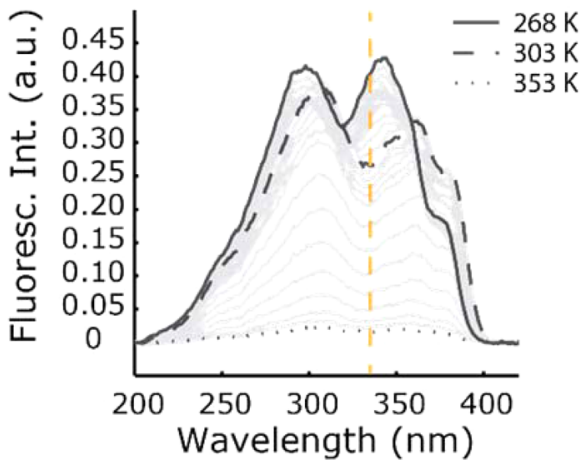

(F)

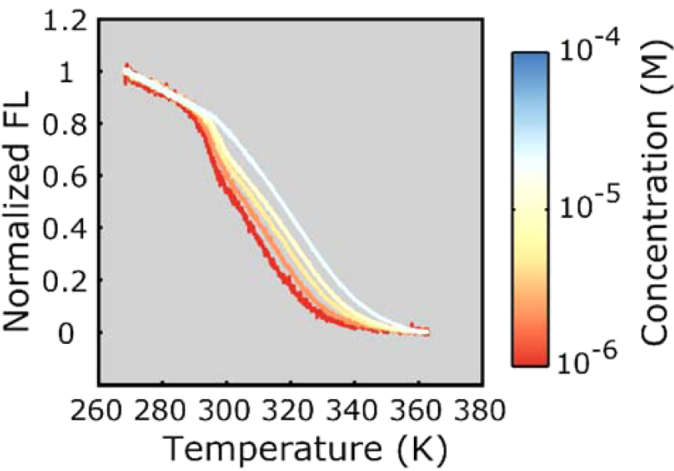

Figure 2. Circular dichroism (A), ultraviolet-visible absorption (B) and fluorescence excitation (C) spectra of $B i P y-1$ in $n$-butanol (1.0 $\left.\times 10^{-5} \mathrm{M}\right)$ at various temperatures. In all graphs, three distinct spectral signatures can be distinguished. Dark gray lines indicate spectra at temperatures where these signatures are most clearly visible, light gray lines are spectra at intermediate temperatures. For all spectra, the BiPy-1 solution was equilibrated prior to acquisition. The detection wavelength for the excitation fluorescence spectra is $\lambda=520 \mathrm{~nm}$. Fluorescence emission spectra are included in Figures SI-4 and SI-5. Panels (D), (E) and (F) show the normalized intensities at $\lambda=335$ nm (orange dotted line in (A-C)) for the CD, UV-vis and FL channels, respectively, as a function of temperature for a range of total monomer concentrations (indicated by the color bar).

been synthesized according to literature procedures. ${ }^{30} \mathrm{We}$ studied the pathway complexity in its self-assembly in $n$-butanol (Figure 1B) using temperature- and concentration-dependent spectroscopic measurements. First, we applied circular dichroism (CD) spectroscopy to probe the macromolecular helicity of the formed assemblies. As shown in Figure 2A, CDspectra of BiPy-1 in $n$-butanol at a concentration of $1.0 \times 10^{-5}$ $\mathrm{M}$ were acquired over a broad temperature range (268-353 K). At temperatures below $293 \mathrm{~K}$, the spectra displayed a large Cotton effect in the $\pi-\pi^{*}$ band around $335 \mathrm{~nm}$ (Figure 2A, solid line), which disappeared above $303 \mathrm{~K}$ (Figure 2A, dashed and dotted lines). In order to probe this transition in detail, the normalized ellipticity at $\lambda=335 \mathrm{~nm}$ was monitored as a function of temperature (Figure 2D). The experimental melting curves show a sharp transition at $295 \mathrm{~K}$, and a shift to higher melting temperatures with increasing concentration (Figure $2 \mathrm{D}$, colors indicate different concentrations).

The self-assembly process was then probed using UV-vis absorption spectroscopy, since the electronic transitions in $B i P y-1$ are sensitive to its molecular environment and thus its aggregate state. ${ }^{30} \mathrm{UV}-$ vis spectra of a $1.0 \times 10^{-5} \mathrm{M}$ solution of $B i P y-1$ in $n$-butanol were acquired at temperatures between 268 and $353 \mathrm{~K}$, as shown in Figure 2B. In these plots, three distinct spectral signatures were identified, which are most pronounced at 268, 303, and $353 \mathrm{~K}$ (Figure 2B, solid, dashed and dotted lines, respectively). The transition regimes were further investigated by plotting the absorbance at $\lambda=335 \mathrm{~nm}$ as a function of temperature (Figure 2E, color bar indicates different concentrations). These traces show the sharp transition around $295 \mathrm{~K}$ also observed in the CD melting curves, but additionally show a second, more gradual transition at higher temperatures.

Next, we investigated the aggregation of $B i P y-1$ using its aggregation-induced fluorescence. ${ }^{30,31}$ In the monomeric state, $B i P y-1$ exhibits rapid nonradiative decay of the excited state, but when the rotational freedom of the bipyridine moieties is restricted, for example due to aggregation, its fluorescence quantum yield is greatly enhanced. The aggregation state of $B i P y-1$ was probed by recording fluorescence excitation spectra at $1.0 \times 10^{-5} \mathrm{M}$ in $n$-butanol over the temperature range of 268 to $353 \mathrm{~K}$ (Figure $2 \mathrm{C}$ ). These spectra, and the fluorescence intensity traces at $\lambda_{\mathrm{exc}}=335 \mathrm{~nm}$ (Figure 2F, colored lines indicate concentration), show negligible emission at a temperature of $353 \mathrm{~K}$ (Figure 2C, dotted line). Cooling to $303 \mathrm{~K}$ (Figure 2C, dashed line) results in gradually increasing fluorescence, concurrent with the high-temperature transition observed in the UV-vis melting curve. Finally, a blue shift in the fluorescence excitation spectra is detected upon further cooling to $295 \mathrm{~K}$, coinciding with the observed increase of the $\mathrm{CD}$ signal in this temperature regime (Figure 2C, solid line).

Based on the spectroscopic measurements shown in Figure 2, three separate states as previously suggested in literature ${ }^{30}$ can be identified. At temperatures above $353 \mathrm{~K}$ (dotted lines in 
(A)

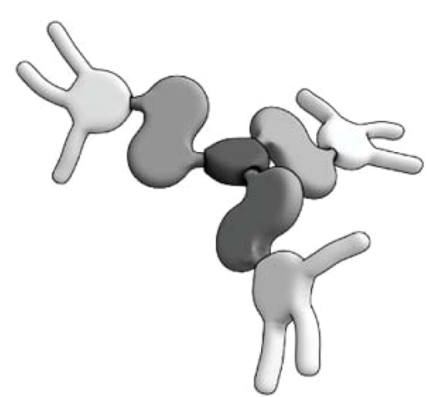

(B)

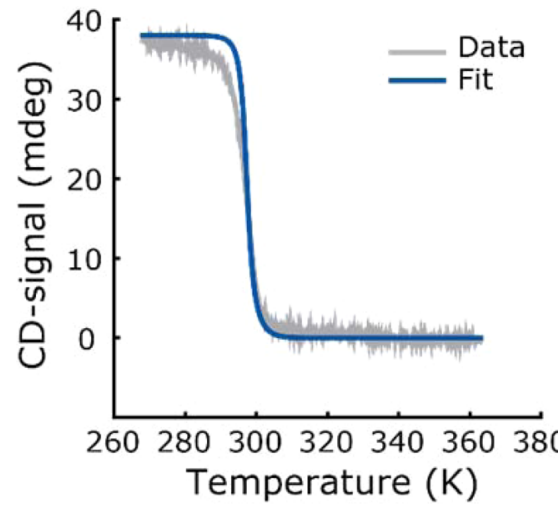

(E)

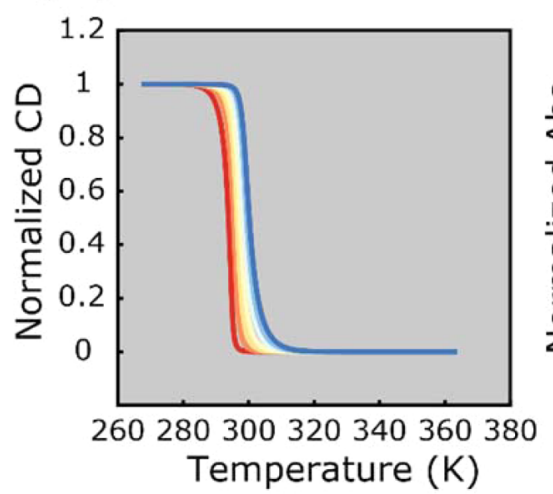

(C)

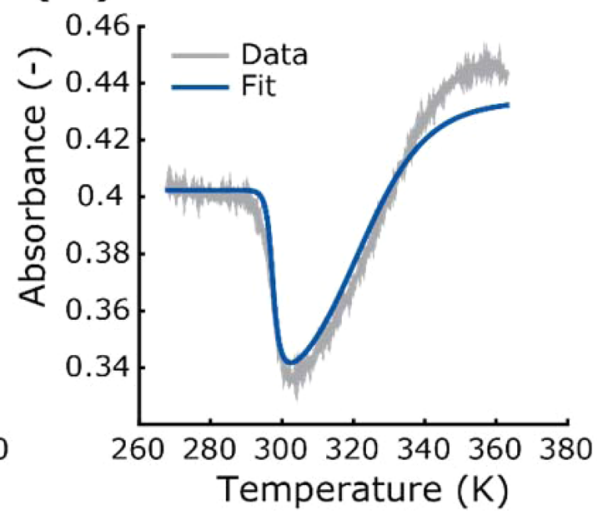

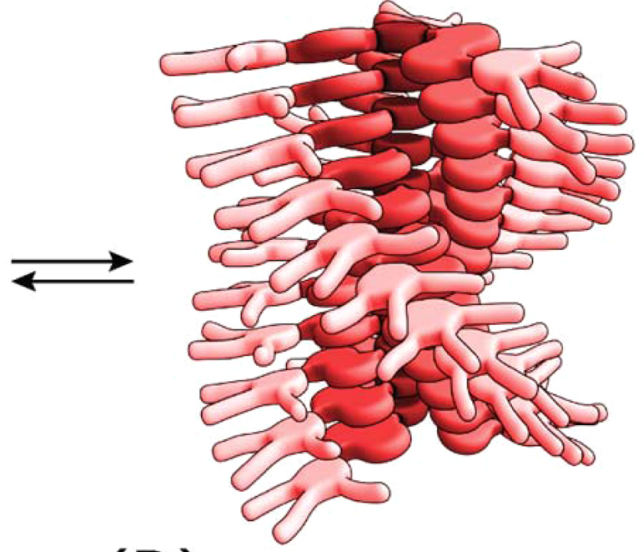

(D)

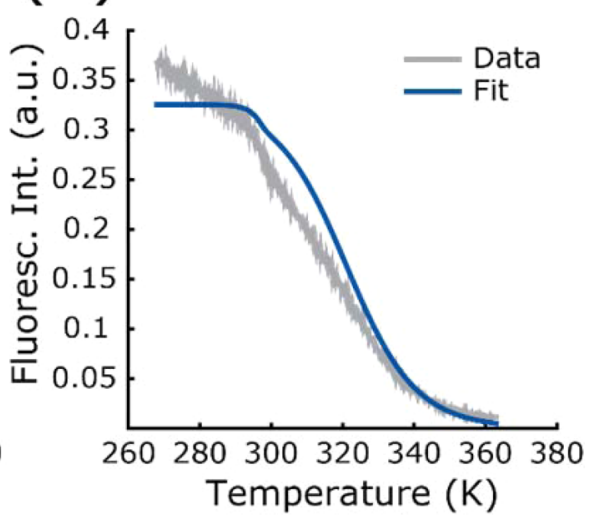

(F)

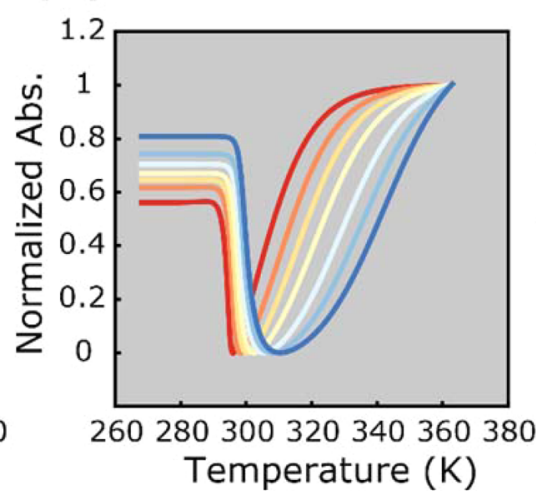

(G)

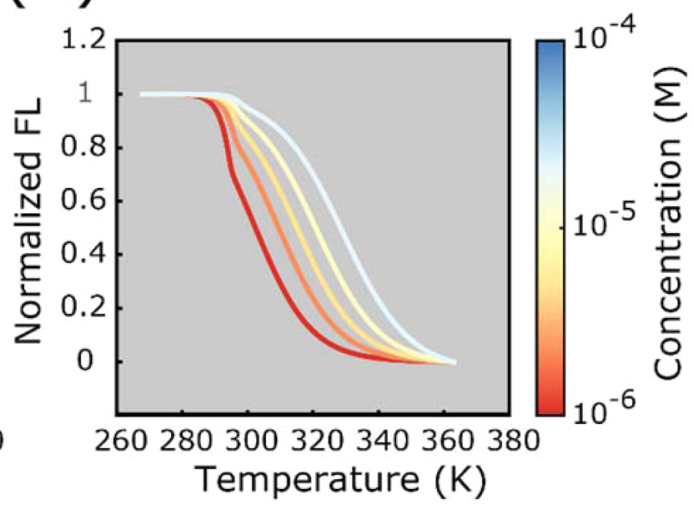

Figure 3. (A) Scheme of a single pathway, cooperative assembly mechanism for BiPy-1. The three spectroscopic signatures are here represented by monomer (gray), disordered prenucleus aggregates (green) and ordered postnucleus aggregates (red). In this model, BiPy-1, present as the monomer at high temperature, partially assembles into aggregates smaller than the nucleus size upon lowering the temperature, to finally grow into long aggregates upon further cooling. (B-D) Temperature-dependent circular dichroism, ultraviolet-visible absorption and fluorescence excitation signal acquired at $[B i P y-1]=1.0 \times 10^{-5} \mathrm{M}$. The single-pathway equilibrium model is fitted to the data (blue lines). (E-G) Simulated temperaturedependent traces in CD, UV-vis and FL channels, using parameter values optimized through a global fitting routine (see SI for details). In these fits, nucleus size $n=8$ has been used. Concentration is indicated by color, and the traces have been normalized for clarity.

Figure $2 \mathrm{~A}-\mathrm{C}$ ), $\mathrm{BiPy}-1$ is present as the monomer in solution, as indicated by the low fluorescence intensity and the absence of a $\mathrm{CD}$ signal. The gradual increase of fluorescence emission intensity and the concomitant red-shift in the UV-spectrum upon cooling signals the formation of a first aggregate state, most clearly visible at $303 \mathrm{~K}$ (dashed lines in Figure 2A-C). The self-assembly of this aggregate takes place over a broad temperature range (Figure $2 \mathrm{D}-\mathrm{F}$, first transition from 353$303 \mathrm{~K}$ ). The low CD signal of this aggregate state proves a lack of macromolecular helicity thus suggesting that the assemblies have a low degree of order. The blue shift observed in UV-vis and fluorescence spectra upon further cooling (Figure 2D-F, second transition from 303-293 K) indicates the formation of a different aggregate state (solid lines in Figure $2 \mathrm{~A}-\mathrm{C}$ ) at low temperature. An intense Cotton effect is observed for this state, suggesting the formation of helical supramolecular structures and proving the transfer of chiral information from the periphery of $B i P y-1$ to the self-assembling core. Similar helical structures have also been proposed for apolar bipyridineextended discotics in methylcyclohexane, ${ }^{28}$ although the exact 
Table 1. Optimized Parameter Values for Global Fitting Procedure Using Single-Pathway Equilibrium Model

$\begin{array}{llll}\Delta H_{n}^{\circ}(\mathrm{kJ} / \mathrm{mol}) & \Delta S_{n}^{\circ}(\mathrm{J} / \mathrm{mol} \mathrm{K}) & \Delta H_{e}^{\circ}(\mathrm{kJ} / \mathrm{mol}) & \Delta S_{e}^{\circ}(\mathrm{J} / \mathrm{mol} \mathrm{K}) \\ -99.41 \pm 0.04 & -218.0 \pm 1.3 & -246.5 \pm 2.3 & -710.5 \pm 7.9\end{array}$

conformation in this solvent differs as indicated by the $\mathrm{CD}$ spectrum.

The structural properties of the different aggregates have been elucidated using temperature- and concentration-dependent spectroscopy, but the details of the interconversion mechanisms between these states are not immediately evident. On the basis of the spectroscopic data, two mechanisms can be hypothesized: (i) BiPy-1 assembles via a single nucleationelongation pathway, and the observed disordered state represents prenucleus aggregates that convert to ordered postnucleus supramolecular polymers at lower temperature, or (ii) BiPy-1 assembles via two parallel pathways, where shorter disordered aggregates compete with longer structured fibers for free monomers. While the direct conversion proposed in the first mechanism is intuitively attractive and often assumed in literature, recent reports increasingly demonstrate the occurrence of parallel-operating, competitive pathways. It is highly challenging to interpret these experimental results in terms of assembly mechanisms and therefore a modeling-based approach is required.

2.2. Equilibrium Single-Pathway Modeling. The mechanistic details of the self-assembly of BiPy-1 were unraveled by employing mathematical models to interpret the multiple spectroscopic transitions (vide supra). First, we apply an equilibrium model that involves a single cooperative nucleationelongation pathway, i.e., a self-assembly pathway in which association of monomer is relatively unfavorable up to a particular aggregate size (the nucleus size $n$ ), and relatively favorable for larger aggregates. In this model, the two aggregate states observed for $B i P y-1$ are interpreted as disordered prenucleus aggregates (i.e., aggregates smaller than the nucleus size and lacking a CD effect) and postnucleus assemblies that show helical order and thus contribute to the CD signal (Figure $3 \mathrm{~A}$ ). The presence of such a disordered prenucleus is common in cooperative systems, and in fact a lack of order in small aggregates is one of the main causes of cooperativity. ${ }^{5 c, 32}$ If both types of aggregates display different spectroscopic signatures, multiple transitions can be observed in temperatureor concentration-dependent experiments, ${ }^{10 b, 33}$ similar to those detected in the melting curves of BiPy-1.

In order to investigate whether the self-assembly of $B i P y-1$ could be correctly explained using a single pathway mechanism, we used the general nucleation-elongation model first reported by Goldstein and Stryer. ${ }^{34}$ This model describes the formation of aggregates in terms of sequential monomer additions with a particular equilibrium constant. Goldstein and Stryer distinguish a nucleation regime with equilibrium constant $K_{n}$ and an elongation regime with equilibrium constant $K_{e}$, for aggregates smaller and larger than the nucleus size $n$, respectively. The relatively unfavorable nucleation in cooperative self-assembly results in a cooperativity parameter $\sigma=K_{n} / K_{e}<1$ and cumulative cooperativity $\omega=\sigma^{n-1}$. In order to describe the experimental melting curves, the van't Hoff equation (eq 1 ) is used to describe the temperature-dependence of the nucleation and elongation equilibrium constants.

$$
\ln (K)=-\frac{\Delta H^{\circ}}{R T}+\frac{\Delta S^{\circ}}{R}
$$

In this expression, $\Delta H^{\circ}$ is the enthalpy change of monomer association and $\Delta S^{\circ}$ is the entropy change of monomer association. Since BiPy-1 moieties adopt dissimilar geometries in prenucleus aggregates and postnucleus aggregates, the values of $\Delta H^{\circ}$ and $\Delta S^{\circ}$ may differ between the two regimes, and consequently the model parameters are varied independently. Equilibrium constants calculated using eq 1 are used to compute the $\mathrm{CD}, \mathrm{UV}$-vis and fluorescence melting curves. A detailed description of this modeling approach used can be found in the Supporting Information.

In order to quantify the self-assembly of $B i P y-\mathbf{1}$ in thermodynamic terms, a global fitting procedure was performed using the single-pathway model. This model utilizes the association enthalpy and entropy parameters as input, and simulates the spectral response for any temperature and concentration. The multiple curve fitting routine incorporates all experimental data simultaneously, and applies nonlinear least-squares minimization combined with Latin Hypercube Sampling to avoid entrapment in local minima. The resulting fit closely reproduces the two experimentally observed processes, i.e., a gradual transition from the monomeric state to prenucleus oligomers when cooling from high temperature and a more rapid second transition to the postnucleus state upon further cooling to below $295 \mathrm{~K}$. Additionally, the concentration dependence of these transitions is in accordance with the experimental melting curves (Figure 2D-F). The major cause for residual deviations between data and best model fit is the assumption that absorption coefficients are constants, which may not hold exactly for all physical conditions.

The fitting procedure shows an initially improving quality of fit with increasing nucleus size, leveling off for $n \geq 8$ (Figure SI1 ), indicating that an oligomeric nucleus is required to explain the experimentally observed behavior. The optimized values for the thermodynamic parameters for the case $n=8$ are shown in Table 1. Clearly, all association enthalpies $\left(\Delta H_{n}^{\circ}\right.$ and $\Delta H_{e}^{\circ}$ for the nucleation and elongation regimes, respectively) and entropies $\left(\Delta S_{n}^{\circ}\right.$ and $\left.\Delta S_{e}^{\circ}\right)$ are negative, indicating an enthalpy-driven self-assembly process. Closer investigation of the obtained parameter values reveals that the two transitions in the experimental cooling curves can be explained through the different temperature-dependencies of the nucleation equilibrium constant $K_{n}$ and the elongation equilibrium constant $K_{e}$ (Figure SI-2). At high temperatures $(T>330-350 \mathrm{~K}$, depending on total concentration $C_{t}$ ), both $K_{n}{ }^{*} C_{t}<1$ and $K_{e}^{*} C_{t}<1$, indicating that no significant aggregation takes place. Upon cooling to intermediate temperatures, $K_{n}{ }^{*} C_{t}>1$ and $K_{e}<$ $K_{n}$, leading to the growth of predominantly prenucleus aggregates, and the observation of a first transition in the UV and fluorescence traces. As observed by $\mathrm{CD}$, further cooling below $295 \mathrm{~K}$ leads to formation of postnucleus supramolecular polymers. This can be explained by the stronger temperature dependence of $K_{e}$ compared to $K_{n}$, resulting in $K_{e}^{*} C_{t}>1$ and $K_{e}$ $>K_{n}$ at low temperatures. Summarizing, our analysis shows that a single-pathway model with $n \geq 8$, in which pre- and postnucleus oligomers have different contributions to the $\mathrm{CD}$, UV and fluorescence signals, is able to describe the two 
(A)
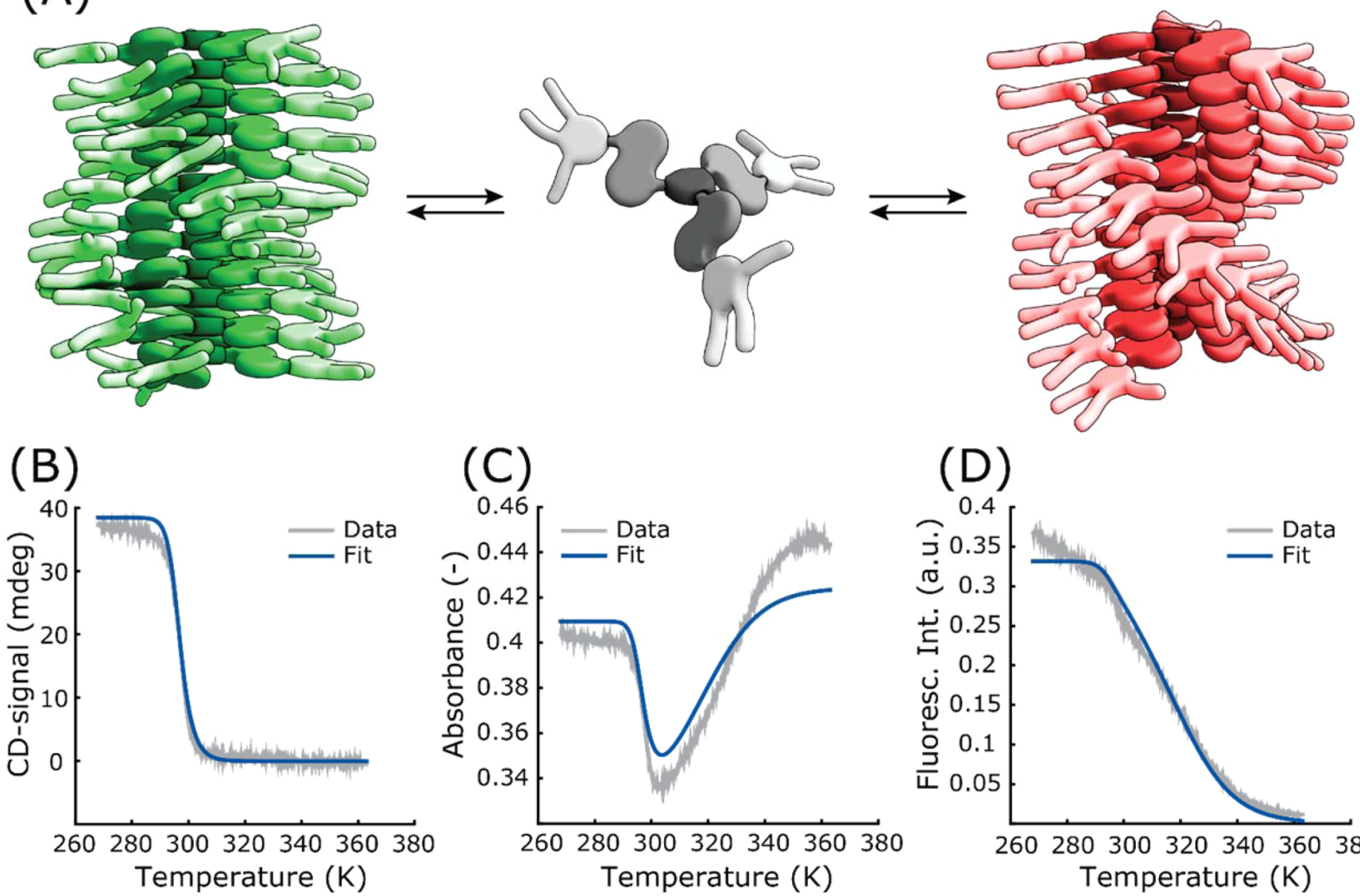

(C)
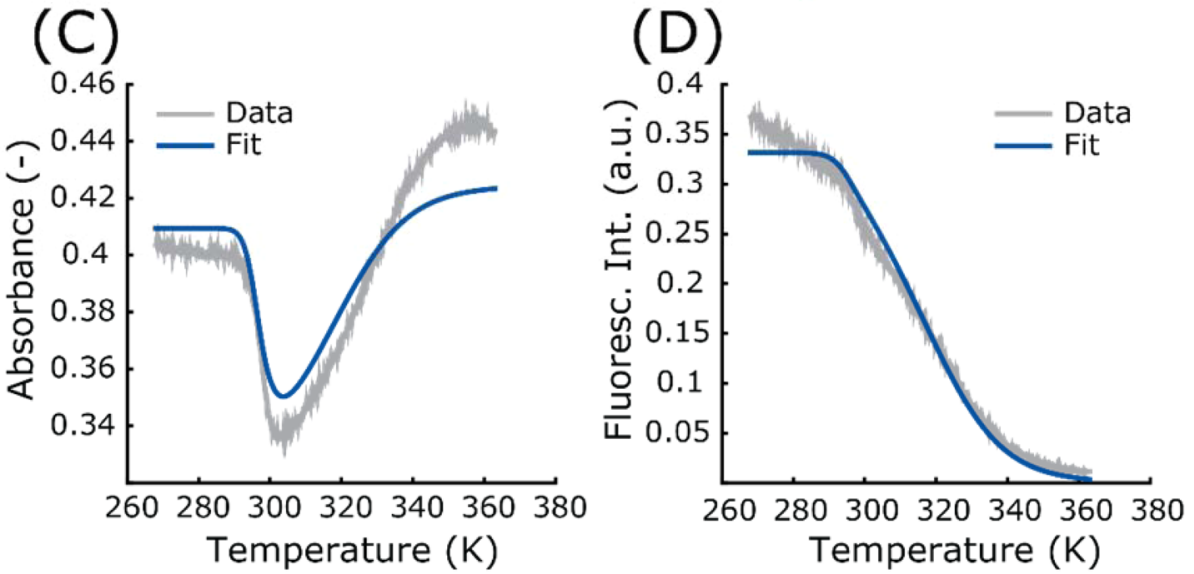

(E)

( $F)$
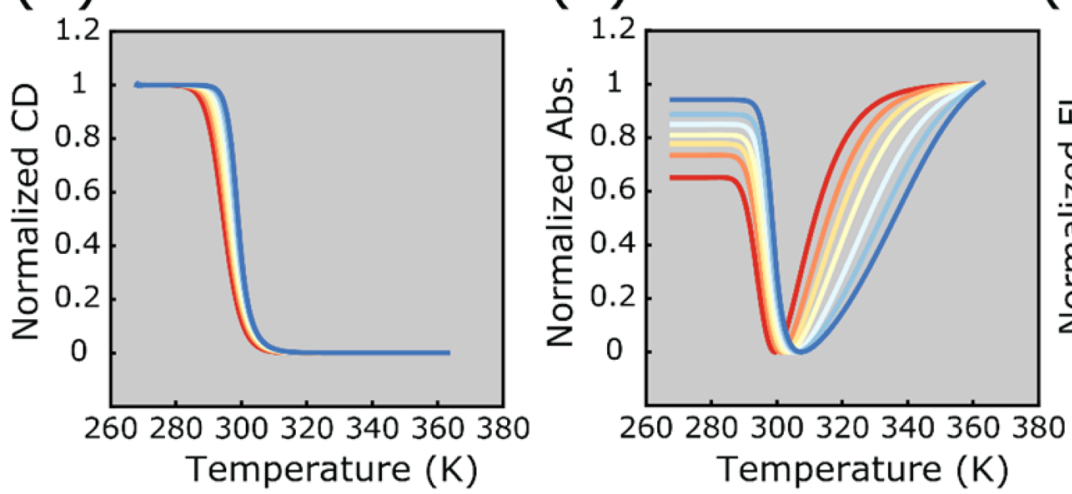

(G)

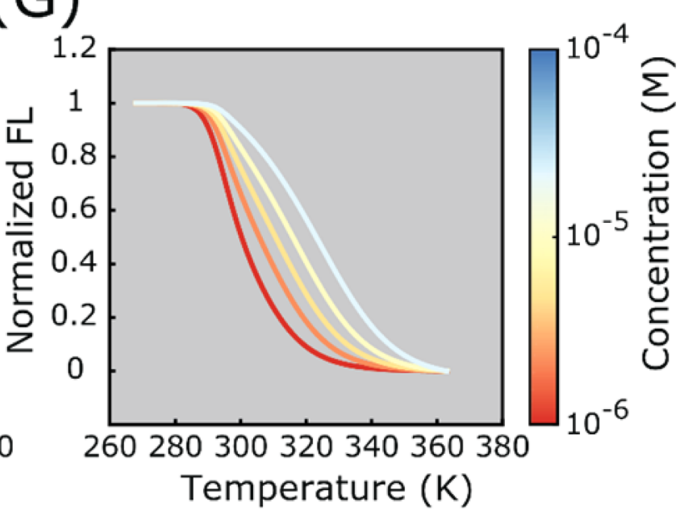

Figure 4. (A) Scheme of an aggregation model with two competitive aggregation pathways for BiPy-1. Here, the three spectroscopic signatures are interpreted as monomer (gray), a disordered aggregate state (green) and an ordered aggregate state (red). At high temperature, $B i P y$ - 1 is present as free monomer, and it initially assembles into disordered aggregates upon lowering the temperature. When cooling to even lower temperature, BiPy-1 dissociates from these aggregates and reassembles along the alternative pathway, forming ordered stacks. (B-D) Circular dichroism, ultravioletvisible absorption and fluorescence excitation signal as a function of temperature, fitted using the two-pathway model (blue lines), overlaid on the experimental measurements (gray lines). Simulations were performed for and experimental traces acquired at $[B i P y-1]=1.0 \times 10^{-5} \mathrm{M}$. $(\mathrm{E}-\mathrm{G})$ Simulated temperature-dependent traces in CD, UV-vis and FL channels, using parameter values optimized through a global fitting routine (see SI for details). Concentration is indicated by color, and the traces have been normalized for clarity.

spectroscopic transitions observed in the aggregation of BiPy-1 in $n$-butanol.

2.3. Equilibrium Two-Pathway Modeling. An alternative method to describe the two experimentally observed transitions is to invoke a model containing two self-assembly pathways that operate in parallel, competing for the same monomer (Figure 4A). In this model, BiPy-1 monomer can assemble into either a disordered aggregate state or a more ordered state, and conversion from one state to the other occurs through monomer dissociation and reassembly into the alternate aggregate type. Models containing competing aggregate states have been proposed for a variety of natural supramolecular polymers, ${ }^{35}$ and have been comprehensively treated mathematically by Powers and Powers. ${ }^{21}$ Recently, similar two-pathway models have been used to explain the aggregation behavior of synthetic supramolecular polymers ${ }^{12 \mathrm{~d}, 23}$ and have been 
exploited to program self-assembly pathways in supramolecular polymerizations. ${ }^{36}$ If both aggregate types have distinct spectroscopic signatures, competition between these pathways could also lead to the observation of multiple aggregate states.

To investigate whether a two-pathway model correctly explains the temperature- and concentration dependent aggregation behavior of $B i P y-1$, we expanded the temperature-dependent Goldstein-Stryer model to include a second, parallel-operating assembly pathway. In contrast to the singlepathway model in which the nucleus size is larger than two, in this model each self-assembly pathway has a nucleus size of two. Furthermore, whereas in the single pathway model the monomer addition entropy changes on going from the nucleation to the elongation phase, we now assume that the monomer addition entropy in each pathway does not change in order to restrict the number of free parameters. In total, the model has six thermodynamic parameters, i.e., in each pathway, aggregation is described by a nucleation and elongation enthalpy and a single association entropy. In the model, either pathway can become thermodynamically stable depending on the total monomer concentration and temperature. In similar fashion to the single-pathway model, the equilibrium constants can be used to calculate the distribution of BiPy-1 over the two aggregate states, and subsequently predict a spectral response (see Supporting Information for details of this model).

After optimization of the input parameters via global nonlinear least-squares analysis, simulations using the twopathway model succeed in reproducing the two experimentally observed transitions as well as their concentration-dependence (Figure 4B-G), again with small residual deviations. The values of the optimized thermodynamic parameters (Table 2) indicate

Table 2. Optimized Parameter Values for Global Fitting Procedure Using Two-Pathway Equilibrium Model

\begin{tabular}{ccc}
$\Delta H_{n, A}^{\circ}(\mathrm{kJ} / \mathrm{mol})$ & $\Delta H_{e, A}^{\circ}(\mathrm{kJ} / \mathrm{mol})$ & $\Delta S_{A}^{\circ}(\mathrm{J} / \mathrm{molK})$ \\
$-103.1 \pm 0.5$ & $-73.17 \pm 5.38$ & $-232.1 \pm 1.7$ \\
$\Delta H_{n, B}^{\circ}(\mathrm{kJ} / \mathrm{mol})$ & $\Delta H_{e, B}^{\circ}(\mathrm{kJ} / \mathrm{mol})$ & $\Delta S_{B}^{\circ}(\mathrm{J} / \mathrm{molK})$ \\
$-326.2 \pm 2.0$ & $-322.6 \pm 1.9$ & $-984.9 \pm 6.7$ \\
\hline
\end{tabular}

that the assemblies in one pathway, termed $A$-type aggregates, self-assemble in an anticooperative fashion while the growth of the $B$-type aggregates in the second pathway is nearly isodesmic. Assembly in both pathways is enthalpically driven, and the transition observed upon cooling from 350 to $305 \mathrm{~K}$ can thus be explained by the association of monomers into Atype aggregates. These aggregates are limited in length, since $K_{n, A}>K_{e, A}$ (i.e., $\sigma<1$ ) in this temperature regime. At temperatures lower than $305 \mathrm{~K}$, the elongation equilibrium constant of the second pathway, $K_{e, B}$ becomes larger than the nucleation constant of $A$-type aggregates $K_{n, A}$ (Figure SI-3) and thus conversion of $A$-type aggregates into $B$-type aggregates occurs. In this temperature regime, growth of $B$-type aggregates takes place in a nearly isodesmic fashion.

This analysis shows that a two-pathway model with an anticooperative and an isodesmic pathway can successfully describe the experimentally observed transitions in the temperature-dependent self-assembly of $B i P y-1$. It is important to realize that both cooperative growth based on sequential monomer addition (i.e., nucleation-elongation) as well as competition based on noncooperative, parallel pathways allow the occurrence of sharp pseudophase boundaries, illustrating that sudden transitions are not necessarily indicative of a strong molecular cooperative effect. Since both an extended-nucleus single-pathway model and a model with two competing pathways can correctly explain the experimental data, we conclude that thermodynamic analysis on itself provides insufficient evidence to distinguish the two self-assembly mechanisms, and we turn to kinetic approaches.

2.4. Temperature-Jump Spectroscopy. Kinetic experiments are established tools for the elucidation of reaction mechanisms and self-assembly pathways, providing information inaccessible by equilibrium approaches. As such, the mechanistic details of BiPy-1 self-assembly in $n$-butanol were further studied using temperature-jump ( $\mathrm{T}$-jump) spectroscopy, a time-resolved method to investigate the kinetics of temperature-sensitive transitions. In T-jump experiments, nearinstantaneous adjustment of temperature is achieved by ultrafast mixing of a $B i P y-1$ sample with an aliquot of solvent at a different temperature, resulting in concurrent concentration and temperature changes. The ensuing mixture is immediately observed using a time-resolved spectrometer in order to track the resulting changes in aggregation state (see Supporting Information for a detailed description of $\mathrm{T}$-jump experiments). Figure 5A shows a simulated population diagram of BiPy-1, illustrating the concentration and temperature dependence of the molecular distribution over the monomeric (gray), disordered aggregate (green) and ordered aggregate (red) states. Clearly, the formation of ordered aggregates is strongly temperature-dependent, making $\mathrm{T}$-jump spectroscopy an attractive method to study the supramolecular polymerization kinetics of this system.

The interconversion mechanism between the different BiPy-1 aggregate morphologies has been investigated by performing $\mathrm{T}$ jump experiments starting at $T_{\text {init }}=313 \mathrm{~K}$ followed by rapid cooling to $T_{\text {final }}=293 \mathrm{~K}$, inducing a transition from the disordered to the ordered aggregate state (Figure 5A, dashed arrows). This process is experimentally observed as a decrease in the total fluorescence intensity upon excitation at $\lambda=380$ $\mathrm{nm}$, occurring on a time scale of $\sim 10 \mathrm{~s}$ (Figure $5 \mathrm{~B}$, colored traces). The rate of the conversion can be quantified using the time to 50 or $90 \%$ completion ( $t-50$ or $t-90$ respectively) after normalization (Figure 5B, black symbols). If the self-assembly of $B i P y-1$ would take place via the two-pathway mechanism, the conversion would involve depolymerization of disordered aggregates to monomers followed by reassembly into the ordered state. On the other hand, if a single pathway mechanism would be operative, depolymerization will not take place as growth occurs from the disordered, prenucleus aggregates. Based on these considerations, the concentrationdependence of the $t-50$ and the $t-90$ is expected to provide decisive information on the self-assembly mechanism. Therefore, $\mathrm{T}$-jump experiments have been performed for a range of concentrations spanning nearly 3 orders of magnitude ([BiPy$1]_{0}=6.8 \times 10^{-7}-3.5 \times 10^{-4} \mathrm{M}$, dashed arrows in Figure $\left.5 \mathrm{~A}\right)$, and the corresponding $\mathrm{t}-50$ and $\mathrm{t}-90$ were determined from the normalized progression curves. The time to completion can be seen to increase monotonically with decreasing concentration (Figure 5B, inset). However, since the slope in the log-log plot is significantly lower than 1 , the concentration dependence is relatively weak. In order to correlate the weak concentrationdependence of t-50 and t-90 to one of the two self-assembly mechanisms, we compared the time-resolved data to kinetic aggregation models.

2.5. ODE-Based Kinetic Modeling. We developed kinetic models for single-pathway and two-pathway self-assembly (vide 
(A)

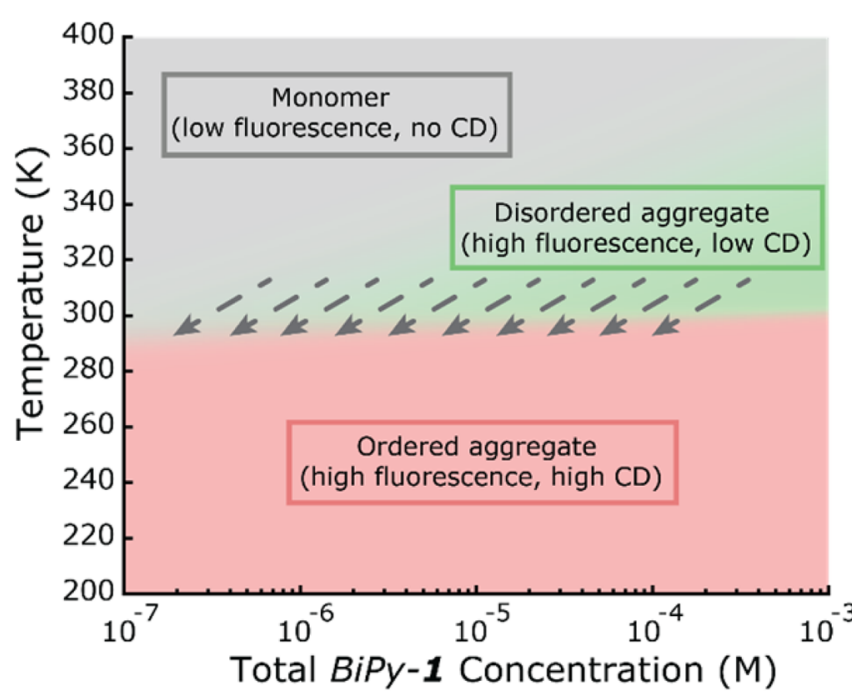

(B)

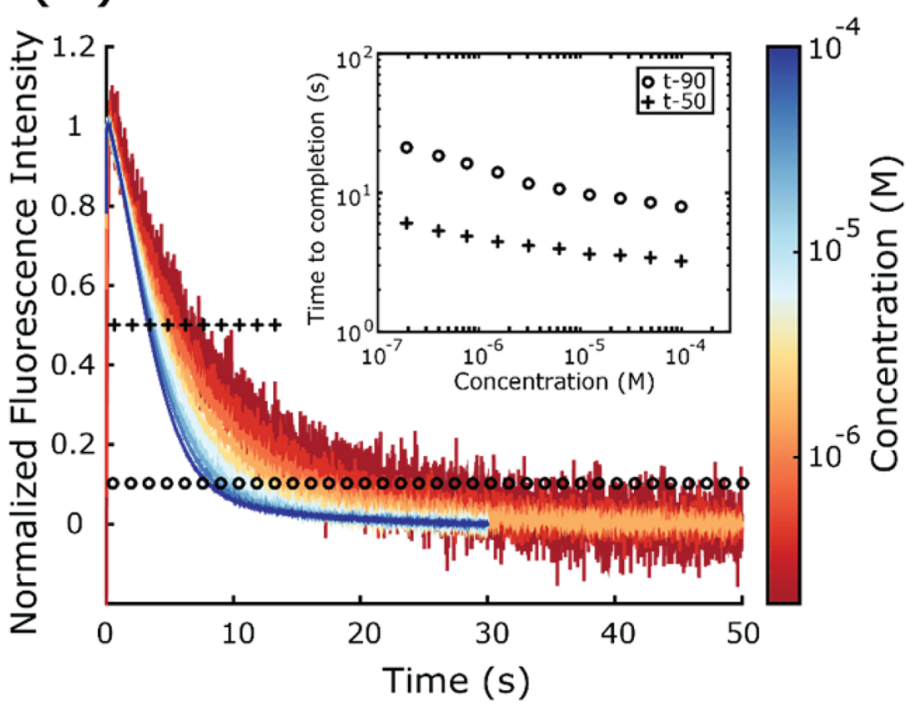

Figure 5. (A) Population diagram for BiPy-1 simulated using the two-pathway model, illustrating its self-assembly behavior as a function of temperature and concentration. At any point in C,T-space, the color quantitatively indicates the amount of BiPy-1 in a particular aggregate state: monomer is indicated in gray, the disordered state is shown in green and the ordered state in red. The arrows indicate the transitions induced in the T-jump experiments. Details of this simulation procedure can be found in the Supporting Information. (B) Time-dependent change in fluorescence intensity of BiPy-1 after a T-jump experiment. T-jump experiments have been performed for a range of concentrations, as indicated by the color bar. All displayed traces are averages of 5 experimental traces and have been normalized. Transition time scales have been extracted by monitoring the time to $50 \%$ completion ( $\mathrm{t}-50$, crosses) or the time to $90 \%$ completion ( $\mathrm{t}-90$, circles). Excitation wavelength $\lambda_{\text {exc }}=380 \mathrm{~nm}$. Inset: Concentration dependence of the $t-50$ and $t-90$.

supra), based on existing models for protein aggregation ${ }^{20 b, 21,37}$ and small-molecule self-assembly. ${ }^{23}$ In general, these kinetic models describe the change rate of aggregate concentrations using the following ordinary differential equation (ODE):

$$
\frac{\mathrm{d}\left[M_{i}\right]}{\mathrm{d} t}=k^{+}[X]\left(\left[M_{i-1}\right]-\left[M_{i}\right]\right)+k^{-}\left(\left[M_{i+1}\right]-\left[M_{i}\right]\right)
$$

In eq $2,\left[M_{i}\right]$ is the concentration of aggregate of length $i$ and $k^{+}$and $k^{-}$are the association and dissociation rate constants, respectively. The two terms of this equation also illustrate that aggregates grow by monomer association and shrink by monomer dissociation. The forward rate constants for nucleation and elongation steps $\left(k_{n}^{+}\right.$and $\left.k_{e}^{+}\right)$can be varied independently, as can the rate constants for different aggregate types $\left(k_{A}^{+}\right.$and $\left.k_{B}^{+}\right)$. Because the association and dissociation rate constants are connected by the corresponding equilibrium constant through the equation $K=k^{+} / k^{-}$, these rate constants cannot be chosen independently. Therefore, the nucleation and elongation equilibrium constants obtained from the nonlinear least-squares optimization of the steady-state data (vide supra) are used as constraints when selecting the rate constants for the kinetic models.

In order to simulate a T-jump experiment, an equilibrium model and corresponding optimized thermodynamic parameters are used to calculate the concentration of all $B i P y-1$ species (i.e., aggregates of different sizes) at $T_{\text {init }}$. Subsequently, the dilution step occurring in the experimental setup is mimicked in the model by dividing these concentrations by the appropriate dilution factor, yielding the initial concentrations of all species. Finally, the equilibrium constants at $T_{\text {final }}$ are calculated using the previously determined enthalpies and entropies and using these parameters as constraints, the system of differential equations is solved using a custom ODE-solver. A detailed description of the kinetic modeling procedure and overview of the full ODE-systems specifying the exact reaction steps for single-pathway and two-pathway models can be found in the Supporting Information.

The single-pathway kinetic model was used to perform Tjump simulations at various total concentrations, in order to investigate the concentration dependence of $t-90$. Figure $6 \mathrm{~A}$ shows the simulated concentration dependence of t-90 (solid line), overlaid by the experimental values (open circles). Clearly, the single-pathway model predicts a strong concentration dependence of the $\mathrm{t}-90$ in the low concentration regime, while at higher concentrations the kinetics become concentration independent. The strong dependence of t-90 at low monomer concentrations $(\log -\log$ slope $<-1)$ and the weak concentration dependence at high concentrations are reminiscent of classical nucleation-dependent kinetic models, ${ }^{37,38}$ and are explained by slow nucleation at lower monomer concentration. To check if this scaling is a general property of the single-pathway model, we performed parameter scans for the two kinetic parameters, $k^{+}$and $r$. Parameter $k^{+}$includes association rate constants for both nucleation and elongation, and a change in $k^{+}$shifts the overall time scale of the transition but does not affect the concentration dependence (Figure 6B). Variations in $r$, the ratio of the association rate constants in the nucleation and elongation regime (i.e., $r=k_{n}^{+} / k_{e}^{+}$), change the limiting concentration at which the $\mathrm{t}-90$ becomes concentration-independent but do not change the slope at low total concentrations (Figure 6C).

The concentration dependence of the $t-90$ for the twopathway model has also been investigated, as shown in Figure 7A (solid line). Using the two-pathway kinetic model, the experimentally observed weak concentration-dependence of the $\mathrm{t}-90$ is closely reproduced by the kinetic simulations over the entire concentration range. The weak scaling is explained by the 


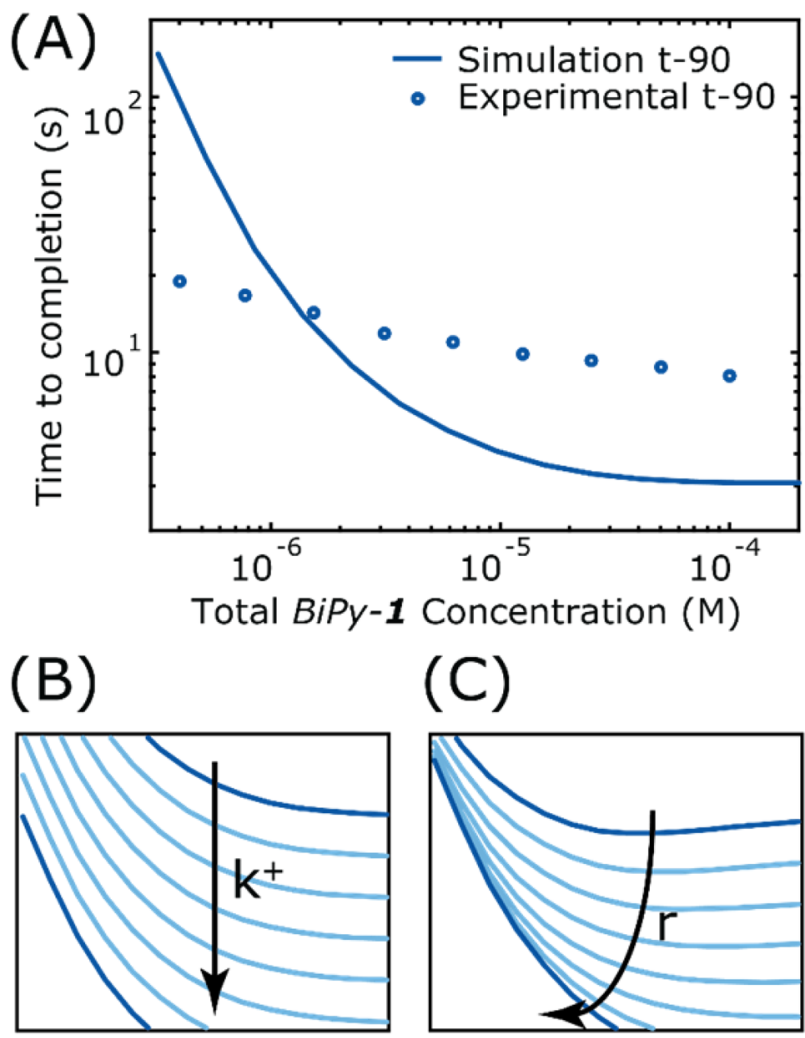

Figure 6. Analysis of T-jump experiments with the single-pathway kinetic model. (A) Concentration-dependence of t-90 determined from the normalized kinetic traces after a T-jump of a solution of BiPy1 in $n$-butanol at $313 \mathrm{~K}$ to a temperature of $293 \mathrm{~K}$. Circles show the experimentally measured $t-90$, while the solid line represents $t-90$ simulated using the single-pathway model with parameter values $k^{+}(\mathrm{L}$. $\left.\mathrm{mol}^{-1} \cdot \mathrm{s}^{-1}\right)=4 \times 10^{7}$ and $r(-)=0.5$. (B,C) The single-pathway model has two free parameters: the combined association rate constant $k^{+}$, and the ratio of association rate constants in the nucleation and elongation regime $r$. Panels (B) and (C) show variation of these parameters over a realistic interval, $10^{6}<k^{+}\left(\mathrm{L} \cdot \mathrm{mol}^{-1} \cdot \mathrm{s}^{-1}\right)<10^{8}$ and $10^{-2}<r(-)<10^{0}$. Axes are identical to (A).

nearly isodesmic characteristics of $B$-type aggregates combined with the presence of strongly anticooperative $A$-type aggregates. At $T_{\text {final }}$, the $A$-pathway is kinetically and thermodynamically accessible since $k_{n, A}^{+}>k_{n, B}^{+}$and $[B i P y-1]>K_{n, A}^{-1}$, leading to sequestration of monomer in small aggregates. Since the $A$-type aggregates are the kinetic species at the final temperature, the amount of BiPy-1 that transiently resides in this pathway is highly dependent on the total concentration. ${ }^{23}$ In a graph plotting t-90 against total concentration, this leads to a slope with an absolute value lower than 1 , which cannot be reproduced by a single-pathway mechanism involving monomer-dependent nucleation. ${ }^{38,39}$ Because of the anticooperativity of pathway $A$, the slope does not increase to positive values at very high concentration, as is observed for cooperative selfassembly. ${ }^{23}$ Variation of the kinetic parameters that control monomer aggregation in pathway $A, k_{A}^{+}$and $r_{A}$, shows that the effect of pathway $A$ on the overall kinetics is indeed stronger at higher concentration due to the higher abundance of $A$-type aggregates (Figure $7 \mathrm{~B}, \mathrm{C}$ ). Altering $k_{B}^{+}$, the rate parameter for pathway $B$, changes the total time scale of the entire selfassembly process (Figure 7D). On the other hand, changing only the nucleation rate constant affects the low-concentration regime most significantly, which is consistent with the slow
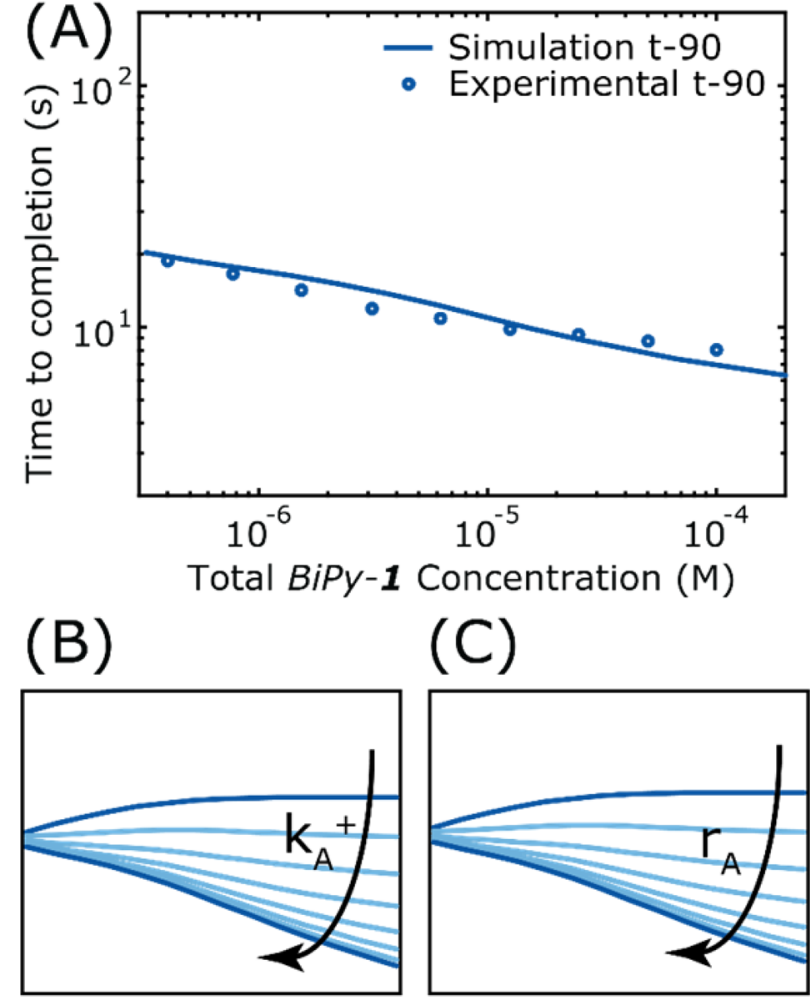

(D)

(E)
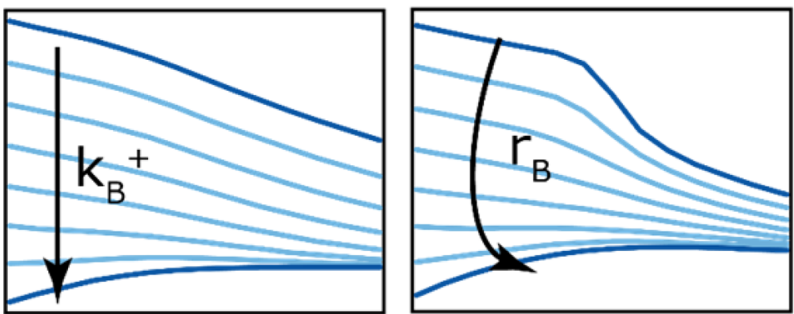

Figure 7. Analysis of T-jump experiments with the two-pathway kinetic model. (A) Concentration-dependence of $t-90$ determined from the normalized kinetic traces after a T-jump of a solution of BiPy1 in $n$-butanol at $313 \mathrm{~K}$ to a temperature of $293 \mathrm{~K}$. Circles show the experimentally measured $\mathrm{t}-90$, the solid line is the $\mathrm{t}-90$ simulated using the two-pathway competitive model with parameter values $k_{A}^{+}(\mathrm{L}$. $\left.\mathrm{mol}^{-1} \cdot \mathrm{s}^{-1}\right)=1 \times 10^{6}, r_{A}(-)=1, k_{B}^{+}\left(\mathrm{L} \cdot \mathrm{mol}^{-1} \cdot \mathrm{s}^{-1}\right)=1 \times 10^{6}$ and $r_{B}$ $(-)=0.25$. (B-E) In the two-pathway model, four parameters can be independently varied; the combined association rate constant for pathways $A$ and $B, k_{A}^{+}$and $k_{B}^{+}$respectively, and the ratio of nucleation and elongation association rate constants for the two pathways, $r_{A}$ and $r_{B}$. These parameters are varied in panels $(\mathrm{B}-\mathrm{E})$, within realistic ranges: $10^{5}<k_{A}^{+}\left(\mathrm{L} \cdot \mathrm{mol}^{-1} \cdot \mathrm{s}^{-1}\right)<10^{7}, 10^{5}<k_{B}^{+}\left(\mathrm{L} \cdot \mathrm{mol}^{-1} \cdot \mathrm{s}^{-1}\right)<10^{7}$, $10^{-1}<r_{A}(-)<10^{1}$ and $10^{-1.5}<r_{B}(-)<10^{0.5}$. Axes are identical to (A).

nucleation at low concentration predicted by theory ${ }^{37}$ (Figure $7 \mathrm{E})$. Comparing these simulations to the T-jump experiments, we find that a single-pathway model is unable to accurately describe the self-assembly of BiPy-1, while a two-pathway model quantitatively reproduces its kinetics. At this point, it is worth noting that while the current two-pathway model provides a minimal description of the experimental observations, the actual system may involve additional equilibria.

These results, combined with equilibrium spectroscopy experiments (vide supra), can elucidate the self-assembly 
behavior of BiPy-1 in molecular terms. The weak concentrationdependence of the kinetics observed in the analysis described here proves that small, disordered $A$-type aggregates compete with, and are kinetically favored over, the more ordered $B$-type structures after rapid cooling. The lack of well-defined structure in A-type aggregates explains the lower barrier for monomer association, and can also explain their anticooperative behavior because the orientational flexibility may lead to inefficient stacking. In this case, nondirectional solvophobic and dipolar interactions promote aggregation but steric effects will limit the aggregate size. The strong temperature-dependence of the formation of B-type aggregates implies that a conformational change is required to self-assemble into this pathway. This likely entails a confinement of the bipyridine wedges to an ordered, ship screw-like conformation ${ }^{28}$ at low temperatures, compatible with a more isodesmic aggregation behavior. Such an ordered conformation is supported by DSC- and SANS data $^{30}$ and agrees well with the tendency of bipyridineextended discotics to form extended helical stacks in a variety of conditions. ${ }^{40}$ From the poor match of the single-pathway model with the kinetic data, we can conclude that disordered aggregates cannot directly nucleate the formation of more ordered stacks, indicating that this conformational change does not take place inside existing $A$-type aggregates. Instead, it is kinetically more favorable to disassemble and reassemble into $B$-type aggregates.

\section{CONCLUSION}

The computational and experimental analysis outlined here illustrates the challenges in achieving mechanistic understanding of aggregation processes. This understanding is critical for optimizing the performance of self-assembled materials, since the assembly mechanism determines how a desired morphology can be formed on a reasonable time scale. Studies of both protein-based and synthetic supramolecular polymers have established a variety of mathematical models for selfassembly processes, recently emphasizing the far-reaching consequences of multiple aggregation pathways for product formation rates. Interpreting experimental data in these complex systems is becoming increasingly challenging, and thus determining the correct aggregation model for a supramolecular polymerization process requires a combination of multiple spectroscopic techniques and numerical modeling.

In this work, we have shown that the appearance of two aggregate signatures in steady-state spectroscopy of BiPy-1 can be explained using either a single-pathway model with a disordered nucleus, or a two-pathway model with two different aggregates competing for the monomer. This observation serves as a reminder that acute transitions can be explained by competition between species in a broad sense, and do not necessarily require highly cooperative assembly pathways. To distinguish the aforementioned two mechanisms, time-resolved T-jump experiments were performed. Since the effects of the simultaneous change in temperature and concentration on the molecular distribution are not easily understood intuitively, ODE-based kinetic models have been applied to explain the spectroscopic transitions. Computational predictions show that a single-pathway model with an extended nucleus cannot reproduce the weak concentration-dependence of BiPy-1 aggregation kinetics. On the contrary, a model with two competing aggregate states can match the experimental results through the interaction of an anticooperative and an isodesmic pathway, thus illustrating how kinetic modeling can distinguish between different possible self-assembly mechanisms for BiPy-1. The two assembly pathways are caused by a temperaturedependent conformational change in the BiPy-1 molecule, leading to different stacking geometries that compete for the monomer and interconvert by disassembly and reaggregation. Establishing this mechanism has important consequences for the formation kinetics of either state, and provides opportunities for directing the assembly toward a desired morphology. Additionally, it warrants the remark that the direct conversion between states often intuitively assumed in literature requires more careful experimental confirmation.

Thus, we show how multiple temperature- and concentration-dependent spectroscopic techniques can be combined to obtain sufficient information about a complex self-assembly process. For a coherent interpretation of these measurements, we employ numerical modeling to combine the disparate data into a global understanding of the self-assembly mechanism, and demonstrate how to validate the choice for a particular model. In this way, we hope to provide a guideline for the elucidation of pathway complexity in supramolecular polymerizations, the thoughtful application of which may reveal counterintuitive mechanistic information. In the near future, the inclusion of modeling avenues for "non-classical" mechanisms, such as the currently intractable dissipative systems, will bring the understanding of self-assembly to a higher level. More generally, such a combined theoretical approach, utilizing coupled thermodynamic and kinetic data, is in our view indispensable in improving the processing of crystalline materials, polymers and any other types of matter aggregating through noncovalent interactions.

\section{EXPERIMENTAL AND COMPUTATIONAL METHODS}

The synthesis of BiPy-1 was performed as described in literature, ${ }^{30}$ and the product was characterized using standard analytical techniques. Spectroscopic experiments were performed at various concentrations and temperatures using spectroscopic grade $n$-butanol. The assembly of $B i P y-1$ under thermodynamic control was probed by $\mathrm{CD}, \mathrm{UV}$ and fluorescence spectroscopy, and the equilibrium conditions were verified by time-dependent control experiments. Temperature-jump experiments were performed by equilibrating a solution of BiPy-1 in $n$ butanol at $T_{\text {init }}$, rapidly mixing this with a volume of $n$-butanol at $T_{2}$ using syringe pumps and a High Density (HDS)-mixer, and injecting the mixed sample into a cuvette at $T_{\text {final }}$. Calibration of the T-jump setup was performed using the temperature-sensitive fluorescent dye $N$-acetyl tryptophan amide (NATA) in $n$-butanol. Equilibrium data were fitted to one- and two-pathway models using a global nonlinear least-squares optimization routine in Matlab (Isqnonlin), which was provided with a range of uniformly sampled starting values by a quasirandom number generator (lhsdesign), ensuring global minimization of the cost function. These models describe the aggregation process of $B i P y-1$ as a series of consecutive monomer association or dissociation steps with a particular equilibrium constant. The equilibrium constants vary between the nucleation $\left(K_{n}\right)$ and elongation $\left(K_{e}\right)$ regimes, and in the two-pathway model also vary between the different pathways $\left(K_{A}\right.$ and $\left.K_{B}\right)$. Temperature-dependence of the equilibrium constants is introduced through the van ' $t$ Hoff equation $K=\exp \left(-\left(\Delta H^{0}-\right.\right.$ $\left.T \Delta S^{0}\right) / R T$ ), and the resulting thermodynamic parameters are optimized as described above. Kinetic ODE-models use the same sequential monomer association-dissociation description for supramolecular polymerization, and track the concentration of aggregates of each size using a separate differential equation. In these kinetic models, the optimized values of the thermodynamic parameters are applied as constraints through $K=k^{+} / k^{-}$, meaning forward and backward rate constants cannot be independently chosen. In order to limit the number of equations, the assumption $\left[X_{i+1}\right]=\alpha\left[X_{i}\right]$ for $i>N(N=$ $1000)$ was used, as introduced in literature. ${ }^{23}$ The resulting system of 
differential equations is solved in Matlab using the custom ODE-solver PPODESUITE.

\section{ASSOCIATED CONTENT}

\section{S Supporting Information}

The Supporting Information is available free of charge on the ACS Publications website at DOI: 10.1021/jacs.5b08138.

Details of spectroscopic measurements, details of the used equilibrium and kinetic models, details and results of the fitting procedure, additional simulated data and additional graphs of thermodynamic properties. (PDF)

\section{AUTHOR INFORMATION}

\section{Corresponding Authors}

*t.f.a.d.greef@tue.nl

*e.w.meijer@tue.nl

\section{Notes}

The authors declare no competing financial interest.

\section{ACKNOWLEDGMENTS}

We would like to thank Prof. Tuomas P.J. Knowles at the University of Cambridge and Dr. Huub ten Eikelder and ir. Tim F.E. Paffen at Eindhoven University of Technology for fruitful discussions. We acknowledge financial support from NWO (ChemThem 728.011.201, VENI 722.012.0001), the Dutch Ministry of Education, Culture and Science (Gravity program 024.001.035) and the European Research Council (FP7/2007-2013, ERC Grant Agreement 246829). The ICMS animation studio is acknowledged for providing the artwork.

\section{REFERENCES}

(1) (a) Whitesides, G.; Mathias, J.; Seto, C. Science 1991, 254, 1312. (b) Lehn, J.-M. Polym. Int. 2002, 51, 825. (c) Brunsveld, L.; Folmer, B. J. B.; Meijer, E. W.; Sijbesma, R. P. Chem. Rev. 2001, 101, 4071. (d) Love, J. C.; Estroff, L. A.; Kriebel, J. K.; Nuzzo, R. G.; Whitesides, G. M. Chem. Rev. 2005, 105, 1103. (e) Jin, Z.; Fan, H. Soft Matter 2014, 10, 9212. (f) Liu, K.; Zhao, N.; Kumacheva, E. Chem. Soc. Rev. 2011, 40, 656. (g) Mühlig, S.; Cunningham, A.; Dintinger, J.; Scharf, T.; Bürgi, T.; Lederer, F.; Rockstuhl, C. Nanophotonics 2013, 2, 211. (h) Stuart, M. A. C.; Huck, W. T. S.; Genzer, J.; Müller, M.; Ober, C.; Stamm, M.; Sukhorukov, G. B.; Szleifer, I.; Tsukruk, V. V.; Urban, M.; Winnik, F.; Zauscher, S.; Luzinov, I.; Minko, S. Nat. Mater. 2010, 9, 101.

(2) (a) Wilner, O. I.; Willner, I. Chem. Rev. 2012, 112, 2528. (b) Takeoka, Y. J. Mater. Chem. C 2013, 1, 6059. (c) Grinthal, A.; Kang, S. H.; Epstein, A.; Aizenberg, M.; Khan, M.; Aizenberg, J. Nano Today 2012, 7, 35. (d) Klajn, R; Stoddart, J. F.; Grzybowski, B. A. Chem. Soc. Rev. 2010, 39, 2203. (e) Warren, S. C.; Walker, D. A.; Grzybowski, B. A. Langmuir 2012, 28, 9093. (f) Yan, X.; Wang, F.; Zheng, B.; Huang, F. Chem. Soc. Rev. 2012, 41, 6042. (g) Krieg, E.; Weissman, H.; Shirman, E.; Shimoni, E.; Rybtchinski, B. Nat. Nanotechnol. 2011, 6, 141. (h) Wang, Q.; Mynar, J. L.; Yoshida, M.; Lee, E.; Lee, M.; Okuro, K.; Kinbara, K.; Aida, T. Nature 2010, 463, 339. (i) Rupar, P. A.; Chabanne, L.; Winnik, M. A.; Manners, I. Science 2012, 337, 559. (j) Cordier, P.; Tournilhac, F.; Soulié-Ziakovic, C.; Leibler, L. Nature 2008, 451, 977. (k) Grzybowski, B. A.; Wilmer, C. E.; Kim, J.; Browne, K. P.; Bishop, K. J. M. Soft Matter 2009, 5, 1110. (1) Rybtchinski, B. ACS Nano 2011, 5, 6791.

(3) (a) Beaujuge, P. M.; Fréchet, J. M. J. J. Am. Chem. Soc. 2011, 133, 20009. (b) Graetzel, M.; Janssen, R. A. J.; Mitzi, D. B.; Sargent, E. H. Nature 2012, 488, 304. (c) Krieg, E.; Shirman, E.; Weissman, H.; Shimoni, E.; Wolf, S. G.; Pinkas, I.; Rybtchinski, B. J. Am. Chem. Soc. 2009, 131, 14365. (d) Babu, S. S.; Praveen, V. K.; Ajayaghosh, A. Chem. Rev. 2014, 114, 1973. (e) Zhang, W.; Jin, W.; Fukushima, T.; Saeki, A.; Seki, S.; Aida, T. Science 2011, 334, 340. (f) Tayi, A. S.;
Shveyd, A. K.; Sue, A. C.-H.; Szarko, J. M.; Rolczynski, B. S.; Cao, D.; Kennedy, T. J.; Sarjeant, A. A.; Stern, C. L.; Paxton, W. F.; Wu, W.; Dey, S. K.; Fahrenbach, A. C.; Guest, J. R.; Mohseni, H.; Chen, L. X.; Wang, K. L.; Stoddart, J. F.; Stupp, S. I. Nature 2012, 488, 485. (g) Henson, Z. B.; Müllen, K.; Bazan, G. C. Nat. Chem. 2012, 4, 699. (h) Sun, Y.; Welch, G. C.; Leong, W. L.; Takacs, C. J.; Bazan, G. C.; Heeger, A. J. Nat. Mater. 2012, 11, 44. (i) Würthner, F.; Meerholz, K. Chem. - Eur. J. 2010, 16, 9366. (j) Briseno, A. L.; Mannsfeld, S. C. B.; Reese, C.; Hancock, J. M.; Xiong, Y.; Jenekhe, S. A.; Bao, Z.; Xia, Y. Nano Lett. 2007, 7, 2847. (k) Zhang, C.; Zou, C.-L.; Yan, Y.; Hao, R.; Sun, F.-W.; Han, Z.-F.; Zhao, Y. S.; Yao, J. J. Am. Chem. Soc. 2011, 133, 7276. (1) Balakrishnan, K.; Datar, A.; Oitker, R.; Chen, H.; Zuo, J.; Zang, L. J. Am. Chem. Soc. 2005, 127, 10496. (m) Oh, J. H.; Lee, H. W.; Mannsfeld, S.; Stoltenberg, R. M.; Jung, E.; Jin, Y. W.; Kim, J. M.; Yoo, J.-B.; Bao, Z. Proc. Natl. Acad. Sci. U. S. A. 2009, 106, 6065.

(4) (a) O'Reilly, R. K.; Hawker, C. J.; Wooley, K. L. Chem. Soc. Rev. 2006, 35, 1068. (b) Löwik, D. W. P. M.; Leunissen, E. H. P.; van den Heuvel, M.; Hansen, M. B.; van Hest, J. C. M. Chem. Soc. Rev. 2010, 39, 3394. (c) Hamley, I. W. Angew. Chem., Int. Ed. 2014, 53, 6866. (d) Ravichandran, R.; Griffith, M.; Phopase, J. J. Mater. Chem. B 2014, 2, 8466. (e) Boekhoven, J.; Stupp, S. I. Adv. Mater. 2014, 26, 1642.

(5) (a) Aida, T.; Meijer, E. W.; Stupp, S. I. Science 2012, 335, 813. (b) Chen, Z.; Lohr, A.; Saha-Möller, C. R.; Würthner, F. Chem. Soc. Rev. 2009, 38, 564. (c) Kulkarni, C.; Balasubramanian, S.; George, S. J. ChemPhysChem 2013, 14, 661.

(6) (a) Sakai, N.; Matile, S. Beilstein J. Org. Chem. 2012, 8, 897. (b) Yamamoto, Y.; Fukushima, T.; Suna, Y.; Ishii, N.; Saeki, A.; Seki, S.; Tagawa, S.; Taniguchi, M.; Kawai, T.; Aida, T. Science 2006, 314, 1761. (c) Haedler, A. T.; Kreger, K.; Issac, A.; Wittmann, B.; Kivala, M.; Hammer, N.; Kohler, J.; Schmidt, H.-W.; Hildner, R. Nature 2015, 523, 196.

(7) (a) Silva, G. A.; Czeisler, C.; Niece, K. L.; Beniash, E.; Harrington, D. A.; Kessler, J. A.; Stupp, S. I. Science 2004, 303, 1352. (b) Shah, R. N.; Shah, N. A.; Del Rosario Lim, M. M.; Hsieh, C.; Nuber, G.; Stupp, S. I. Proc. Natl. Acad. Sci. U. S. A. 2010, 107, 3293.

(8) (a) Spano, F. C.; Silva, C. Annu. Rev. Phys. Chem. 2014, 65, 477. (b) Ortony, J. H.; Newcomb, C. J.; Matson, J. B.; Palmer, L. C.; Doan, P. E.; Hoffman, B. M.; Stupp, S. I. Nat. Mater. 2014, 13, 812.

(9) (a) Bong, D. T.; Clark, T. D.; Granja, J. R.; Ghadiri, M. R. Angew. Chem., Int. Ed. 2001, 40, 988. (b) Simic, V.; Bouteiller, L.; Jalabert, M. J. Am. Chem. Soc. 2003, 125, 13148. (c) Yao, S.; Beginn, U.; Gress, T.; Lysetska, M.; Würthner, F. J. Am. Chem. Soc. 2004, 126, 8336. (d) Cantekin, S.; de Greef, T. F. A.; Palmans, A. R. A. Chem. Soc. Rev. 2012, 41, 6125. (e) Mayoral, M. J.; Rest, C.; Stepanenko, V.; Schellheimer, J.; Albuquerque, R. Q.; Fernandez, G. J. Am. Chem. Soc. 2013, 135, 2148. (f) Jalani, K.; Kumar, M.; George, S. J. Chem. Commun. 2013, 49, 5174.

(10) (a) Mann, S. Nat. Mater. 2009, 8, 781. (b) Jonkheijm, P.; van der Schoot, P.; Schenning, A. P. H. J.; Meijer, E. W. Science 2006, 313, 80. (c) Gopal, A.; Hifsudheen, M.; Furumi, S.; Takeuchi, M.; Ajayaghosh, A. Angew. Chem., Int. Ed. 2012, 51, 10505. (d) Hu, J.; Kuang, W.; Deng, K.; Zou, W.; Huang, Y.; Wei, Z.; Faul, C. F. J. Adv. Funct. Mater. 2012, 22, 4149. (e) Levin, A.; Mason, T. O.; AdlerAbramovich, L.; Buell, A. K.; Meisl, G.; Galvagnion, C.; Bram, Y.; Stratford, S. A.; Dobson, C. M.; Knowles, T. P. J.; Gazit, E. Nat. Commun. 2014, 5, 5219.

(11) (a) Jian, C.; Tang, T. J. Phys. Chem. B 2014, 118, 12772. (b) Kumar, M.; Brocorens, P.; Tonnelé, C.; Beljonne, D.; Surin, M.; George, S. J. Nat. Commun. 2014, 5, 5793. (c) Pop, F.; Melan, C.; Danila, I.; Linares, M.; Beljonne, D.; Amabilino, D. B.; Avarvari, N. Chem. - Eur. J. 2014, 20, 17443. (d) Olivier, Y.; Niedzialek, D.; Lemaur, V.; Pisula, W.; Müllen, K.; Koldemir, U.; Reynolds, J. R.; Lazzaroni, R.; Cornil, J.; Beljonne, D. Adv. Mater. 2014, 26, 2119.

(12) (a) Bouteiller, L.; Colombani, O.; Lortie, F.; Terech, P. J. Am. Chem. Soc. 2005, 127, 8893. (b) Bellot, M.; Bouteiller, L. Langmuir 2008, 24, 14176. (c) Eakins, G. L.; Gallaher, J. K.; Keyzers, R. A.; Falber, A.; Webb, J. E. A.; Laos, A.; Tidhar, Y.; Weissman, H.; Rybtchinski, B.; Thordarson, P.; Hodgkiss, J. M. J. Phys. Chem. B 2014, 118, 8642. (d) Fennel, F.; Wolter, S.; Xie, Z.; Plötz, P.-A.; Kühn, O.; 
Würthner, F.; Lochbrunner, S. J. Am. Chem. Soc. 2013, 135, 18722.

(e) Baram, J.; Weissman, H.; Rybtchinski, B. J. Phys. Chem. B 2014,

118, 12068. (f) Van der Schoot, P.; Michels, M. A. J.; Brunsveld, L.;

Sijbesma, R. P.; Ramzi, A. Langmuir 2000, 16, 10076.

(13) Markvoort, A. J.; ten Eikelder, H. M. M.; Hilbers, P. A. J.; de

Greef, T. F. A.; Meijer, E. W. Nat. Commun. 2011, 2, 509.

(14) Mitchison, T.; Kirschner, M. Nature 1984, 312, 237.

(15) Wu, H. Cell 2013, 153, 287.

(16) Albertazzi, L.; van der Zwaag, D.; Leenders, C. M. A.; Fitzner, R.; van der Hofstad, R. W.; Meijer, E. W. Science 2014, 344, 491.

(17) (a) Cui, H.; Chen, Z.; Zhong, S.; Wooley, K. L.; Pochan, D. J. Science 2007, 317, 647. (b) Mattia, E.; Otto, S. Nat. Nanotechnol. 2015, 10, 111.

(18) Oosawa, F.; Kasai, M. J. Mol. Biol. 1962, 4, 10.

(19) (a) Wegner, A.; Savko, P. Biochemistry 1982, 21, 1909. (b) Knowles, T. P. J.; Waudby, C. A.; Devlin, G. L.; Cohen, S. I. A.; Aguzzi, A.; Vendruscolo, M.; Terentjev, E. M.; Welland, M. E.; Dobson, C. M. Science 2009, 326, 1533.

(20) (a) Bishop, M. F.; Ferrone, F. A. Biophys. J. 1984, 46, 631. (b) Ferrone, F. A.; Hofrichter, J.; Eaton, W. A. J. Mol. Biol. 1985, 183, 611. (c) Ferrone, F. Methods Enzymol. 1999, 309, 256.

(21) Powers, E. T.; Powers, D. L. Biophys. J. 2008, 94, 379.

(22) (a) Lohr, A.; Würthner, F. Angew. Chem., Int. Ed. 2008, 47, 1232. (b) Korevaar, P. A.; Schaefer, C.; de Greef, T. F. A.; Meijer, E. W. J. Am. Chem. Soc. 2012, 134, 13482. (c) Korevaar, P. A.; Grenier, C.; Markvoort, A. J.; Schenning, A. P. H. J.; de Greef, T. F. A.; Meijer, E. W. Proc. Natl. Acad. Sci. U. S. A. 2013, 110, 17205. (d) Korevaar, P. A.; de Greef, T. F. A.; Meijer, E. W. Chem. Mater. 2014, 26, 576.

(e) Cremades, N.; Cohen, S. I. A.; Deas, E.; Abramov, A. Y.; Chen, A. Y.; Orte, A.; Sandal, M.; Clarke, R. W.; Dunne, P.; Aprile, F. A.; Bertoncini, C. W.; Wood, N. W.; Knowles, T. P. J.; Dobson, C. M.; Klenerman, D. Cell 2012, 149, 1048. (f) Liang, C.; Ni, R.; Smith, J. E.; Childers, W. S.; Mehta, A. K.; Lynn, D. G. J. Am. Chem. Soc. 2014, 136, 15146.

(23) Korevaar, P. A.; George, S. J.; Markvoort, A. J.; Smulders, M. M. J.; Hilbers, P. A. J.; Schenning, A. P. H. J.; De Greef, T. F. A.; Meijer, E. W. Nature 2012, 481, 492.

(24) Ogi, S.; Sugiyasu, K.; Manna, S.; Samitsu, S.; Takeuchi, M. Nat. Chem. 2014, 6, 188.

(25) Kang, J.; Miyajima, D.; Mori, T.; Inoue, Y.; Itoh, Y.; Aida, T. Science 2015, 347, 646.

(26) Ogi, S.; Stepanenko, V.; Sugiyasu, K.; Takeuchi, M.; Würthner, F. J. Am. Chem. Soc. 2015, 137, 3300.

(27) van der Zwaag, D.; de Greef, T. F. A.; Meijer, E. W. Angew. Chem., Int. Ed. 2015, 54, 8334.

(28) Metzroth, T.; Hoffmann, A.; Martín-Rapún, R.; Smulders, M. M. J.; Pieterse, K.; Palmans, A. R. A.; Vekemans, J. A. J. M.; Meijer, E. W.; Spiess, H. W.; Gauss, J. Chem. Sci. 2011, 2, 69.

(29) Brunsveld, L.; Lohmeijer, B. G. G.; Vekemans, J. A. J. M.; Meijer, E. W. Chem. Commun. 2000, 2305.

(30) Brunsveld, L.; Zhang, H.; Glasbeek, M.; Vekemans, J. A. J. M.; Meijer, E. W. J. Am. Chem. Soc. 2000, 122, 6175.

(31) Hong, Y.; Lam, J. W. Y.; Tang, B. Z. Chem. Soc. Rev. 2011, 40, 5361.

(32) (a) Zhao, D.; Moore, J. S. Org. Biomol. Chem. 2003, 1, 3471.

(b) de Greef, T. F. A.; Smulders, M. M. J.; Wolffs, M.; Schenning, A. P. H. J.; Sijbesma, R. P.; Meijer, E. W. Chem. Rev. 2009, 109, 5687. (c) Rest, C.; Kandanelli, R.; Fernandez, G. Chem. Soc. Rev. 2015, 44, 2543.

(33) Fernández, G.; Stolte, M.; Stepanenko, V.; Würthner, F. Chem. -

Eur. J. 2013, 19, 206.

(34) Goldstein, R. F.; Stryer, L. Biophys. J. 1986, 50, 583.

(35) (a) Souillac, P. O.; Uversky, V. N.; Millett, I. S.; Khurana, R.; Doniach, S.; Fink, A. L. J. Biol. Chem. 2002, 277, 12657. (b) Kaylor, J.; Bodner, N.; Edridge, S.; Yamin, G.; Hong, D.-P.; Fink, A. L. J. Mol. Biol. 2005, 353, 357. (c) Sabareesan, A. T.; Udgaonkar, J. B. Biochemistry 2014, 53, 1206.

(36) Ogi, S.; Fukui, T.; Jue, M. L.; Takeuchi, M.; Sugiyasu, K. Angew. Chem., Int. Ed. 2014, 53, 14363.
(37) Powers, E. T.; Powers, D. L. Biophys. J. 2006, 91, 122.

(38) Kodaka, M. Biophys. Chem. 2004, 109, 325.

(39) Cohen, S. I. A.; Linse, S.; Luheshi, L. M.; Hellstrand, E.; White, D. A.; Rajah, L.; Otzen, D. E.; Vendruscolo, M.; Dobson, C. M.; Knowles, T. P. J. Proc. Natl. Acad. Sci. U. S. A. 2013, 110, 9758.

(40) (a) Brunsveld, L.; Vekemans, J. A. J. M.; Janssen, H. M.; Meijer, E. W. Mol. Cryst. Liq. Cryst. Sci. Technol., Sect. A 1999, 331, 449. (b) Brunsveld, L.; Lohmeijer, B. G. G.; Vekemans, J. A. J. M.; Meijer, E. W. Chem. Commun. 2000, 23, 2305. (c) Müller, M. K.; Petkau, K.; Brunsveld, L. Chem. Commun. 2010, 47, 310. 